\title{
Melissa officinalis Essential Oil: Chemical Compositions, Antioxidant Potential, Total Phenolic Content and Antimicrobial Activity
}

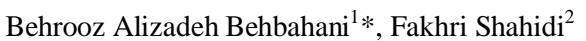

1- Department of Food Science and Technology, Faculty of Animal Science and Food Technology, Agricultural Sciences and Natural Resources University of Khuzestan, Mollasani, Iran

2- Department of Food Science and Technology, Faculty of Agriculture, Ferdowsi University of Mashhad, Mashhad, Iran

\section{A B S T R A C T}

Background and Objectives: Melissa officinalis belongs to plant Lamiaceae family and is native to Iran as well as other countries. The aim of this study was to identify chemical compositions and antioxidant activity of the M. officinalis essential oil (EO). Another aim of this paper was to assess antimicrobial activity of M. officinalis EO on growth of clinical and commercial strains causing infection.

Materials and Methods: Chemical compositions of the M. officinalis EO were analyzed using gas chromatographymass spectrometry (GC-MS). The antioxidant potential was assessed using $\beta$-carotene/linoleic acid inhibition and 2,2diphenyl-1-picrylhydrazyl methods. The total phenol content was analyzed using Folin-Ciocalteu method. Antimicrobial activities of the M. officinalis EO were assessed using disk diffusion agar, well diffusion agar, micro-well dilution, agar dilution and minimum bactericidal concentration (MBC) methods.

Results: Major compositions of the M. officinalis EO included geranyl acetate (27.9\%), citral (14.2\%), Z-citral (9.8\%) citronellal (8.4\%) and citronellol (7.6\%). The total phenolic content and antioxidant potential of the M. officinalis EO included $51 \pm 0.50 \mathrm{mg} \mathrm{GAE} / \mathrm{g}$ and $98 \pm 0.45 \mu \mathrm{g} / \mathrm{ml}$, respectively. Minimum inhibitory concentration (MIC) of the $M$. officinalis EO ranged $0.5-4 \mathrm{mg} / \mathrm{ml}$, while the MBC ranged $1-8 \mathrm{mg} / \mathrm{ml}$. A significant correlation was seen between the inhibition zone diameters (IZD) and concentration of the EO. The smallest IZD was reported for various concentrations of the M. officinalis EO on Pseudomonas aeruginosa.

Conclusions: In general, results showed that the M. officinalis EO included greater inhibitory effects on commercial bacterial strains causing infections, compared to those of clinical bacterial strains. The $M$. officinalis EO have the greatest effect on gram-positive bacteria. This compound is an effective free radical scavenger rich in phenolic compounds. Further studies are necessary to investigate toxicity of the M. officinalis EO due to its safety for human use.

Keywords: Melissa officinalis, Microbial pathogenesis, Inhibition zone diameter, Chemical composition

\section{Introduction}

Treatment of microbial infections is mostly based on the use of common therapeutic antibiotics. Since the common therapeutic antibiotics are extensively used, the pathogenic microorganisms have mostly become resistant to these chemicals Furthermore, common therapeutic antibiotics are usually associated with adverse effects including hypersensitivity, immune-suppression and allergic responses. Therefore, screening of the antimicrobial activities of medicinal herbs for the treatment of infections is as natural substitutions of the current chemical antibiotics [1-6]. Essential oils (EO) and secondary metabolites of herbs have many uses in medicine as we as food and hygiene industries [7,8]. The herbal EO includes various health features including antioxidant and antimicrobial activities [7,9]. Various forms of the activated oxygen, also known as reactive oxygen species (ROS), include free radicals and nonfree radical species. [10]. The ROS exert oxidative stress in human body and break its antioxidant defense mechanism; hence, the free radicals assault cell macromolecules resulting in several physiological 
disorders [11]. Relatively, studies have shown that use of chemical preservatives for long terms may result in the prevalence of various cancers. Therefore, use of chemical preservatives has been decreased during the last few decades. Indeed, use of medicinal herbs as preservatives has recently been increased due to their less unwanted side effects $[12,13]$. Lemon balm with the scientific name of Melissa officinalis belongs to Lamiaceae family of plants and is native to Iran, Central Asia and Europe. In many countries, $M$. officinalis has been cited as a mild sedative, spasmolytic and antimicrobial agent. The $M$. officinalis EO has been reported as an antibacterial, antifungal and antiparasitic compound [14-17]. The main purpose of this study was to investigate chemical compositions and antioxidant activities of the M. officinalis EO. Another purpose of the study was to assess antimicrobial activities of the $M$. officinalis EO on growth of clinical and commercial bacterial strains causing infections.

\section{Materials and Methods}

\section{Chemicals, reagents and microbial media}

Chemicals such as dimethyl sulphoxide (DMSO), butylated hydroxyl toluene (BHT), $\beta$-carotene linoleic acid (ß-CL), 2,3,5-triphenyl-tetrazolium chloride (TTC) and 2,2-diphenyl-1-picrylhydrazyl (DPPH) used in this study were purchased from SigmaAldrich, USA. Bacteriological peptone broth (BDH Chemicals, UK), tryptone soy broth (TSB) and sodium chloride (East Anglia Chemicals, UK) were also purchased. All solvents used in the study included analytical grades provided by Merck, Germany. All microbial media, Mueller-Hinton agar (MHA) and Mueller-Hinton broth (MHB), were provided by Merck, Germany.

\section{Preparation of Melissa officinalis essential oil}

After verification of the plants, collected plants were dried in shade at ambient temperature to a constant weight and then powdered using laboratory grinder. The EO was extracted according to the European Pharmacopoeia protocol. Briefly, 20 gr of the powdered $M$. officinalis were exposed to hydrodistillation for $1.5 \mathrm{~h}$ using Clevenger. The EO was dried using anhydrous sodium sulfate $\left(\mathrm{Na}_{2} \mathrm{SO}_{4}\right)$ and then stored at $4{ }^{\circ} \mathrm{C}$ in glass vials until used in biological studies [18]. The extraction yield of $M$. officinalis EO was assessed based on a method by Noshad et al., 2018 [19].

\section{Essential oil analysis (phytochemical and chemical components)}

Phytochemical analysis of the M. officinalis EO was carried out based on the qualitative methods. Briefly, phenolic (ferric chloride), flavonoids (Shinoda test), saponins (Froth test) and alkaloids (Mayer and Bosshardt) were analyzed [18, 19]. Chemical compositions of the M. officinalis EO were analyzed using gas chromatography/mass spectrometry (GC-MS) [21]. In general, $0.1 \mu \mathrm{l}$ of the M. officinalis EO was injected into the GC-MS. Carrier helium gas was used at a flow rate of 1 $\mathrm{ml} / \mathrm{min}$ and an ionization energy of $70 \mathrm{eV}$. The individual compositions were identified via analogy of their mass spectra and retention indices (RI) with those of the valid samples and those given in the literature.

\section{Estimation of total phenolic content (TPC)}

The Folin-Ciocalteu method was used using TPC. Results were presented as $\mathrm{mg}$ of gallic acid (GA)/g of the dried M. officinalis EO [22].

\section{Antioxidant potential}

The antioxidant potential of the EO was estimated using 2,2-diphenyl-1-picrylhydrazyl (DPPH) (SigmaAldrich, USA) protocol described by Alizadeh Behbahani and Imani Fooladi in 2018 [23] and Alizadeh Behbahani et al. in 2017 [24]. The radical scavenging activity percentage of DPPH was computed using the following equation (1):

Scavenging activity $(\%)=($ Abs control - Abs sample $/$ Abs control) $\times 100$

Concentration of the $M$. officinalis EO that inhibited $50 \%$ of the DPPH radicals was reported as IC $_{50}$ value. Methods of Ozturk et al., (2011) [25] and Noshad et al., (2018) [19] were used for B-carotenelinoleic acid assay ( $(-C L)$. The average inhibition rate was calculated using the following equation (2):

Inhibition rate $(\%)=\left[\left(\mathrm{AA}_{120}-\mathrm{AC}_{120}\right) /\left(\mathrm{AC}_{0}-\mathrm{AC}_{120}\right)\right] \times$ 100

Where, $\mathrm{AA}_{120}, \mathrm{AC}_{120}$ and $\mathrm{AC}_{0}$ were the absorbance for the antioxidant potential of samples after $120 \mathrm{~min}$, control samples after 120 min and control samples at the beginning of the experiment $(t=0)$, respectively. 


\section{Preparation of the bacterial strains}

The commercial strains (Pseudomonas aeruginosa ATCC 27853, Escherichia coli ATCC 25922, Staphylococcus epidermidis ATCC 12228 and Streptococcus pyogenes ATCC 19615) and clinically isolated strains ( $P$. aeruginosa, E. coli, S. epidermidis and $S$. pyogenes) causing infections were provided by the Laboratory of Industrial Microbiology, Ferdowsi University of Mashhad (FUM), Mashhad, Iran. Identification of the clinical strains causing infections was carried out through biochemical tests [26].

\section{Suspension preparation}

All bacteria were cultivated on MHA under aerobic conditions for $24 \mathrm{~h}$ at $37{ }^{\circ} \mathrm{C}$. Freshly cultured commercial strain and clinically isolated strain colonies were suspended in $10 \mathrm{ml}$ of normal saline. Then, bacterial concentrations were adjusted to $1.5 \times$ $10^{8} \mathrm{CFU}$ (colony forming units) $/ \mathrm{ml}$ based on 0.5 McFarland [27].

\section{Antimicrobial activity assay}

Disc diffusion agar (DDA): Antimicrobial activity of the EO was assessed using DDA method [28]. In this method, $0.1 \mathrm{ml}$ of the incubated bacterial (either clinical or commercial) suspension was spread on MHA plates. Concentrations of $0.5,1,2,4$ and 8 $\mathrm{mg} / \mathrm{ml}$ of the EO were prepared in dimethyl sulfoxide (DMSO) solvent. These were sterilized using $0.22-\mu \mathrm{m}$ syringe microfilters. A paper disc with $6.2 \mathrm{~mm}$ in diameter (Padtanteb, Iran) was infused with $20 \mu \mathrm{l}$ of the M. officinalis EO and placed on inoculated MHA plates. The culture media containing either clinical or commercial bacterial strain were incubated at $37{ }^{\circ} \mathrm{C}$ for $24 \mathrm{~h}$. Finally, IZD (mm) around the disks was measured using ruler and recorded [13, 21].

Well diffusion agar (WDA): Antimicrobial activity of the EO was assessed using WDA method [29]. In this method, 5 wells were created on the surface of MHA plates using of Pasteur pipettes. A $0.1 \mathrm{ml}$ of the incubated bacterial (either clinical and or commercial) suspension was spread on the culture media. Concentrations of $0.5,1,2,4$ and $8 \mathrm{mg} / \mathrm{ml}$ of the EO were prepared. Then, $20 \mu \mathrm{l}$ of each concentration was poured into a well. A well was left as blank. After incubation for $24 \mathrm{~h}$ at $37^{\circ} \mathrm{C}$, plates were studied for IZD [30].

Microwell plate dilution assay: The MIC of the $M$. officinalis EO against the commercial strains causing infections and clinically isolated strains was assessed using micro-well dilution assay according to the protocols by the Clinical and Laboratory Standards Institute (CLSI, 2006a, b, c) [31-33]. Final concentration of the M. officinalis EO in the 96-well plate ranged $0.5-16 \mathrm{mg} / \mathrm{ml}$. Then, the $96-$ well plate was incubated at $37{ }^{\circ} \mathrm{C}$ for $24 \mathrm{~h} \mathrm{[34].} \mathrm{After}$ incubation, $20 \mu \mathrm{l}$ of 5\% 2,3,5-triphenyl-tetrazolium chloride was added to each well. The first concentration, at which the red color was not observed, was considered as MIC [35, 36].

Agar dilution method (ADM): The ADM method was used according to the instruction by CLSI; modified by Wiegand et al. (2008) [37] and Noshad et al. (2018) [19].

Minimum bactericidal concentration (MBC): The MBC was assessed using pour plate method [38]. Briefly, $100 \mu \mathrm{l}$ of the solution from the wells free of red color (the MIC test) were cultured on MHA plates. The first concentration with bacterial growth on MHA was reported as MBC $[19,29]$.

\section{Statistical analysis}

All experiments were carried out in triplicate. The SPSS software (IBM Analytics, USA) was used to analyze data. Data were considered as significant when $P \leq 0.05$.

\section{Results}

\section{Chemical composition, phytochemical analysis and antioxidant potential}

Analysis of the $M$. officinalis EO extraction showed that $0.1 \mathrm{ml}$ of the EO was obtained from $20 \mathrm{~g}$ of the M. officinalis with an extraction yield of $0.5 \%$ $(\mathrm{v} / \mathrm{w})$. Results of the EO composition analysis by GCMS showed that the total composition constituted nearly $96.7 \%$ of the EO. Geranyl acetate with $27.9 \%$ was the major compound of the M. officinalis EO (Table 1).

Table 1. Chemical compositions of the Melissa officinalis essential oil

\begin{tabular}{lll}
\hline No. & Compound & $\%$ \\
\hline 1 & Geranyl acetate & 27.9 \\
2 & Citral & 14.2 \\
3 & Z-citral & 9.8 \\
4 & Citronellal & 8.4 \\
5 & Citronellol & 7.6 \\
6 & Geraniol & 5.31 \\
7 & (Z)-nerol & 5.26 \\
8 & Germacrene-D & 5.20 \\
9 & Nerol & 3.45 \\
10 & Linalool & 1.01 \\
\hline Compounds with percentages less than one are not shown in the
\end{tabular}
table 
Other principal components included citral, Zcitral, geraniol, (Z)-nerol, germacrene-D, nerol, linalool, citronellal and citronellol. Results of the total phenolic content and antioxidant activity of the $M$. officinalis EO are shown in Table 2. Results from the identification of $M$. officinalis EO phytochemical analysis revealed that the essential oil contained alkaloids (yellow or brown), flavonoids (red solution) saponins (formation of a stable foam) and phenolics (green-bluish). Total phenolic content and antioxidant potential of the $M$. officinalis EO included51 \pm 0.50 $\mathrm{mg} \mathrm{GAE} / \mathrm{g}$ and $98 \pm 0.45 \mu \mathrm{g} / \mathrm{ml}$, respectively. The $\beta$ carotene/linoleic acid inhibition test for assessing the antioxidant potential of $M$. officinalis EO showed a $25.22 \%$ value.

\section{Antimicrobial activity}

Antibacterial effects of the M. officinalis EO on growth of clinical and commercial strains causing infections were investigated usingDDA method (Table 3). Results showed that the M. officinalis EO included the most antimicrobial effect on $S$. pyogenes (commercial strain) at $8 \mathrm{mg} / \mathrm{ml}$. The smallest IZD of various $M$. officinalis $\mathrm{EO}$ concentrations belonged to gram-negative bacteria (clinical strains). Results showed no IZD for $P$. aeruginosa (clinical strain) at concentrations of 0.5 and $1 \mathrm{mg} / \mathrm{ml}$. No IZD was seen for $E$. coli (clinical strain) and $P$. aeruginosa (commercial strain) at concentration of $0.5 \mathrm{mg} / \mathrm{ml}$. The IZD was observed at all M. officinalis EO concentrations for $S$. pyogenes and $S$. epidermidis. Results demonstrated that the highlighted bacteria were significantly different $(P \leq 0.05)$ in susceptibility to various concentrations of the $M$. officinalis EO using DDA method. Pairwise comparison of the effects of $M$. officinalis EO concentrations on the bacteria (commercial and clinical strains) showed no significant differences. As the concentration increased, the IZD increased too. However, as shown in Table 3, no significant differences $(P \leq 0.05)$ were seen between the concentrations of 4 and $8 \mathrm{mg} / \mathrm{ml}$ in $E$. coli and $S$. pyogenes (clinical strains).

Table 2. Phytochemical analysis, total phenolic contents and antioxidant potentials of the Melissa officinalis essential oil

\begin{tabular}{llll}
\hline Chemical & Verification method & Observation & Occurrence \\
\hline Alkaloids & Mayer and Bosshardt & Formation of a yellow or brown color & + \\
Flavonoids & Shinoda test & Red solution & + \\
Saponins & Froth test & Formation of a stable foam & + \\
Phenolics & Ferric chloride & Green-bluish & +++ \\
IC & - & - & $98.00 \pm 0.45 \mu \mathrm{g} / \mathrm{ml}$ \\
B-CL & - & - & $25.22 \%$ \\
TPC & - & - & $51.00 \pm 0.50 \mathrm{mg} \mathrm{GAE} / \mathrm{g}$ \\
BHT & - & - & $11.20 \pm 0.50 \mu \mathrm{g} / \mathrm{ml}$ \\
Control & & & 0
\end{tabular}

+present in small concentrations; ++present in moderately high concentrations; $\mathrm{IC}_{50}$, the half maximal inhibitory concentration; $\beta-\mathrm{CL}, \beta$-carotene linoleic acid; TPC, total phenolic content; BHT, butylated hydroxyl toluene

Table 3. Mean inhibition zone diameters $(\mathrm{mm})$ of Melissa officinalis essential oil on clinical and commercial bacterial strains causing infections (DDA)

\begin{tabular}{|c|c|c|c|c|c|c|}
\hline Microorganism & Concentration & $0.5 \mathrm{mg} / \mathrm{ml}$ & $1 \mathrm{mg} / \mathrm{ml}$ & $2 \mathrm{mg} / \mathrm{ml}$ & $4 \mathrm{mg} / \mathrm{ml}$ & $8 \mathrm{mg} / \mathrm{ml}$ \\
\hline \multicolumn{7}{|l|}{ Clinical strain } \\
\hline P. aeruginosa & & - & - & $7.30 \pm 0.50^{\mathrm{a}}$ & $9.10 \pm 0.50^{\mathrm{b}}$ & $10.60 \pm 0.54^{\mathrm{c}}$ \\
\hline E. coli & & - & $7.00 \pm 0.50^{\mathrm{a}}$ & $8.60 \pm 0.52^{\mathrm{b}}$ & $10.30 \pm 0.54^{\mathrm{c}}$ & $11.00 \pm 0.52^{\mathrm{c}}$ \\
\hline S. epidermidis & & $7.00 \pm 0.52^{\mathrm{a}}$ & $9.00 \pm 0.45^{\mathrm{b}}$ & $10.60 \pm 0.50^{\mathrm{c}}$ & $12.40 \pm 0.54^{\mathrm{d}}$ & $13.50 \pm 0.52^{\mathrm{d}}$ \\
\hline S. pyogenes & & $7.30 \pm 0.50^{\mathrm{a}}$ & $9.00 \pm 0.50^{\mathrm{b}}$ & $11.00 \pm 0.50^{\mathrm{c}}$ & $12.60 \pm 0.50^{\mathrm{d}}$ & $14.40 \pm 0.54^{\mathrm{e}}$ \\
\hline \multicolumn{7}{|c|}{ Commercial strain } \\
\hline P. aeruginosa & & - & $7.10 \pm 0.50^{\mathrm{a}}$ & $8.40 \pm 0.45^{\mathrm{b}}$ & $10.00 \pm 0.52^{\mathrm{c}}$ & $11.80 \pm 0.50^{\mathrm{d}}$ \\
\hline E. coli & & $6.50 \pm 0.34^{\mathrm{a}}$ & $7.30 \pm 0.54^{\mathrm{a}}$ & $9.00 \pm 0.50^{\mathrm{b}}$ & $10.80 \pm 0.50^{\mathrm{c}}$ & $11.80 \pm 0.50^{\mathrm{c}}$ \\
\hline S. epidermidis & & $7.70 \pm 0.50^{\mathrm{a}}$ & $9.10 \pm 0.50^{\mathrm{b}}$ & $11.20 \pm 0.45^{\mathrm{c}}$ & $13.80 \pm 0.50^{\mathrm{d}}$ & $14.50 \pm 0.50^{\mathrm{d}}$ \\
\hline S. pyogenes & & $8.20 \pm 0.45^{\mathrm{a}}$ & $9.80 \pm 0.35^{\mathrm{b}}$ & $11.90 \pm 0.50^{\mathrm{c}}$ & $14.30 \pm 0.52^{\mathrm{d}}$ & $15.10 \pm 0.52^{\mathrm{d}}$ \\
\hline
\end{tabular}


Results of the antibacterial effects of $M$. officinalis EO using WDA method are shown in Table 4. These results revealed that the $M$. officinalis EO was effective on gram-positive bacteria ( $S$. epidermidis and $S$. pyogenes) as well as gram-negative bacteria $(E$. coli) at all concentrations. However, no IZD was observed for the gram-negative bacteria ( $P$. aeruginosa) at $0.5 \mathrm{mg} / \mathrm{ml}$ concentration. Furthermore, results showed that the IZD values in WDA method were greater than those in DDM method. In WDA method, the IZD values were greater than those in DDA method due to direct contacts between the antimicrobial agents and the bacteria. A significant correlation was seen between the IZD value and the concentration of the EO. The smallest IZD value belonged to the various concentrations of $M$. officinalis EO on $P$. aeruginosa. Results showed that the $M$. officinalis EO included a greater inhibitory effect on the commercial strains causing infections, compared to that on clinical strains. The largest mean IZD of $15.80 \pm 0.52 \mathrm{~mm}$ at $8 \mathrm{mg} / \mathrm{ml}$ concentrations belonged to $S$. pyogenes. Results of MIC, MBC and antibiofilm activities of the $M$. officinalis EO are summarized in Table 5. The MIC of M. officinalis EO ranged $0.5-4 \mathrm{mg} / \mathrm{ml}$, while $\mathrm{MBC}$ ranged $1-8 \mathrm{mg} / \mathrm{ml}$. The MIC of M. officinalis EO included 0.5, 1, 4 and 4 $\mathrm{mg} / \mathrm{ml}$ for $S$. pyogenes, S. epidermidis, E. coli and $P$. aeruginosa (commercial strains), respectively. The MBC of $M$. officinalis EO included 1, 1, 4 and 8 $\mathrm{mg} / \mathrm{ml}$ for S. pyogenes, S. epidermidis, E. coli and $P$. aeruginosa (commercial strains), respectively. The MIC of $M$. officinalis EO included 1, 2, 4 and 4 $\mathrm{mg} / \mathrm{ml}$ for $S$. pyogenes, $S$. epidermidis, E. coli and $P$. aeruginosa (clinical strains), respectively. The MBC of M. officinalis EO included 2, 2, 8 and $8 \mathrm{mg} / \mathrm{ml}$ for $S$. pyogenes, $S$. epidermidis, E. coli and $P$. aeruginosa (clinical strains), respectively.

Table 4. Mean inhibition zone diameters $(\mathrm{mm})$ of the Melissa officinalis essential oil on clinical and commercial bacterial strains causing infections (WDA)

\begin{tabular}{|c|c|c|c|c|c|c|}
\hline Microorganism & Concentration & $0.5 \mathrm{mg} / \mathrm{ml}$ & $1 \mathrm{mg} / \mathrm{ml}$ & $2 \mathrm{mg} / \mathrm{ml}$ & $4 \mathrm{mg} / \mathrm{ml}$ & $8 \mathrm{mg} / \mathrm{ml}$ \\
\hline \multicolumn{7}{|l|}{ Clinical strain } \\
\hline P. aeruginosa & & - & $6.80 \pm 0.50^{\mathrm{a}}$ & $8.20 \pm 0.50^{\mathrm{b}}$ & $9.70 \pm 0.50^{c}$ & $11.00 \pm 0.50^{\mathrm{c}}$ \\
\hline E. coli & & $6.70 \pm 0.50^{\mathrm{a}}$ & $7.80 \pm 0.50^{\mathrm{a}}$ & $9.00 \pm 0.50^{\mathrm{a}}$ & $10.80 \pm 0.52^{\mathrm{b}}$ & $12.00 \pm 0.52^{\mathrm{b}}$ \\
\hline S. epidermidis & & $7.60 \pm 0.50^{\mathrm{a}}$ & $9.00 \pm 0.50^{\mathrm{a}}$ & $11.10 \pm 0.52^{\mathrm{b}}$ & $13.20 \pm 0.50^{\mathrm{c}}$ & $14.70 \pm 0.52^{\mathrm{d}}$ \\
\hline S. pyogenes & & $8.20 \pm 0.50^{\mathrm{a}}$ & $9.80 \pm 0.50^{\mathrm{b}}$ & $12.00 \pm 0.54^{\mathrm{c}}$ & $14.50 \pm 0.50^{\mathrm{d}}$ & $15.10 \pm 0.50^{\mathrm{d}}$ \\
\hline \multicolumn{7}{|c|}{ Commercial strain } \\
\hline P. aeruginosa & & - & $7.20 \pm 0.50^{\mathrm{a}}$ & $8.80 \pm 0.45^{\mathrm{b}}$ & $10.10 \pm 0.50^{\mathrm{b}}$ & $11.20 \pm 0.54^{\mathrm{b}}$ \\
\hline E. coli & & $7.00 \pm 0.50^{\mathrm{a}}$ & $7.90 \pm 0.54^{\mathrm{a}}$ & $9.20 \pm 0.50^{\mathrm{a}}$ & $11.00 \pm 0.50^{\mathrm{b}}$ & $12.30 \pm 0.50^{\mathrm{b}}$ \\
\hline S. epidermidis & & $8.00 \pm 0.52^{\mathrm{a}}$ & $9.30 \pm 0.50^{\mathrm{a}}$ & $11.40 \pm 0.50^{\mathrm{b}}$ & $14.00 \pm 0.52^{\mathrm{c}}$ & $15.10 \pm 0.50^{c}$ \\
\hline S. pyogenes & & $8.60 \pm 0.45^{\mathrm{a}}$ & $10.10 \pm 0.50^{\mathrm{b}}$ & $12.30 \pm 0.50^{\mathrm{c}}$ & $14.90 \pm 0.52^{\mathrm{d}}$ & $15.80 \pm 0.52^{\mathrm{d}}$ \\
\hline
\end{tabular}

Table 5. Minimum inhibitory concentration and minimum bactericidal concentration of the Melissa officinalis essential oil on clinical and commercial bacterial strains causing infections

\begin{tabular}{lccc}
\hline Microorganism & MIC (micro-well dilution) $(\mathrm{mg} / \mathrm{ml})$ & MIC (agar dilution) $(\mathrm{mg} / \mathrm{ml})$ & $\mathrm{MBC}(\mathrm{mg} / \mathrm{ml})$ \\
\hline Clinical strain & & & 8 \\
$P$. aeruginosa & 4 & $\leq 4$ & 8 \\
E. coli & 4 & $\leq 2$ & 2 \\
S. epidermidis & 2 & $\geq 1$ & 2 \\
S. pyogenes & 1 & & 8 \\
Commercial strain & & $>4$ & 4 \\
P. aeruginosa & 4 & $\leq 4$ & 1 \\
E. coli & 4 & $\geq 1$ & 1 \\
S. epidermidis & 1 & $\geq 0.5$ & \\
S. pyogenes & 0.5 & & \\
\hline
\end{tabular}




\section{Disc ussion}

\section{Chemical composition, phytochemical analysis and antioxidant activity}

In 2003, Sadraei et al. [16] showed that the $M$. officinalis EO contained $0.1 \%(\mathrm{v} / \mathrm{w})$ of yellowish EO. Their results demonstrated that 17 constituents identified in M. officinalis EO accounted for $98.1 \%$ of the total oil composition. In 2004, de Sousa et al. [15] demonstrated that the yield of M. officinalis EO included $0.97 \%(\mathrm{v} / \mathrm{w})$. Pouyanfar et al. (2018) [17] reported that the average $M$. officinalis EO yield included $0.13-0.35 \%(\mathrm{w} / \mathrm{w})$. During the growth cycles, the environmental agents such as amount of existing water are very important in yield of dried materials and EOs [17, 39]. Mimica-Dukic et al. (2004) [40] studied the M. officinalis EO chemical compositions. They showed that the chemical compositions $M$. officinalis EO included monoterpene aldehydes, ketones and sesquiterpene. Adinee et al. (2008) [41] investigated the $M$. officinalis EO chemical compositions. They reported that trans-carveol was dominant within the components. Other principal components included trans-carveol (28.89\%), citronellol (25.24\%), $\square-3$ carene $(5.26 \%)$, citronellal $(4.9 \%)$, geraniol $(2.2 \%)$, 1-octene-3-ol $(2.03 \%)$ and spathulenol $(2.06 \%)$. In 2004, de Sousa et al. [15] reported that the major compositions in 13 EOs included limonene-10-ol, geraniol and caryophyllene oxide. These were reported from various countries previously. Chung et al. (2010) [14] showed 40 compositions in EO of the Melissa officinalis leaves. These majorly included monoterpene hydrocarbons, sesquiterpene hydrocarbons and oxygenated monoterpenes. In 2014, Uyanik and Gurbuz [42] demonstrated that citral, caryophyllene oxide and zcitral (in leaves and flowers), caryophyllene oxide, citral and $\beta$ caryophyllene (in whole plant) were dominant within the components. Bozovic et al. (2018) [43] reported cis-caryophyllene and its oxide form as the major EO constituents; similar to reports from the current study. Alizadeh Behbahani et al. (2017) showed that the chemical compounds of the EO varied depending upon the herbal variety, growth stage, and collection time and the climatic condition [20]. Previously, Mimica-Dukic et al. (2004) [40] showed thatthe $M$. officinalis EO exhibited a very strong free radical scavenging capacity, reducing the DPPH radical formation $\left(\mathrm{IC}_{50}=7.58 \mu \mathrm{g} / \mathrm{ml}\right)$ and $\mathrm{OH}$ radical generation $\left(\mathrm{IC}_{50}=1.74 \mu \mathrm{g} / \mathrm{ml}\right)$ in a dose-dependent manner. Researches have demonstrated a direct relationship between the total phenolic content and the antioxidant potential [20,29].

\section{Antimicrobial activity}

Many herb EOs owe their ability to the presence of substances such as alkaloids, tannins, glycosides, flavones, anthraquinones, flavonoids, terpenes, anthocyanins, phenolics and aldehydes. These substances are generally found in multiple parts of the herbs, including leaves, roots, shoots, blossoms, flowers and barks. Many herbs have thus become the origins of major drugs and the pharmaceutical industries have become interested in these herbs as sources of bioactive factors [44-46]. Results of this study plainly revealed that the $M$. officinalis EO antibacterial activities on the growth of clinical and commercial strains causing infections. The effectiveness of the active components in herb EOs results in visible IZD surrounding the antimicrobial paper disks. However, some herbal EOs were unable to exhibit antimicrobial activity on clinical and commercial bacterial strains causing infections. The IZD of the M. officinalis EO varied from $10.60 \mathrm{~mm}$ at $8 \mathrm{mg} / \mathrm{ml}$ concentrations for $P$. aeruginosa to $14.40 \mathrm{~mm}$ at $8 \mathrm{mg} / \mathrm{ml}$ concentrations for $S$. pyogenes. In general, resistance profile of the clinical and commercial strains causing infections was as follows: P. aeruginosa $>$ E. coli $>S$. epidermidis $>S$. pyogenes. According to studies, gram-negative bacteria are more resistant to the EO than gram-positive bacteria due to the external cell walls $[13,19,20]$. Results showed that MBC of the M. officinalis EO was seen at higher concentrations than MIC. Therefore, this suggested that the antibacterial substances in the EO were bacteriostatic at lower and bactericidal at higher concentrations. In 2004, Mimica-Dukic et al. [40] tested antimicrobial effects of the $M$. officinalis EO on bacterial ( $P$. aeruginosa, E. coli, S. aureus, S. epidermidis, Shigella sonnei, Sarcina lutea, Micrococcus flavus, Bacillus subtilis, Salmonella enteritidis and S. typhi) and six fungi (Trichophyton mentagrophytes, $T$. rubrum, T. tonsurans, Microsporum canis, Epidermophyton floccosum and Candida albicans) strains in vitro. Their reported that the most effective antimicrobial was expressed on a multi-resistant 
strain of $S$. sonnei. A significant rate of antifungal effects was exhibited in Trichophyton spp. Studies have been carried out on antimicrobial effects of herbal EOs on gram-negative and gram-positive bacteria by Yeganagi et al., (2018) [47], Noshad et al. (2018) [19], Alizadeh Behbahani and Imani Fooladi (2018) [23] and Alizadeh Behbahani et al. (2017, 2018) [21, 28]. In these studies, gramnegative bacteria were more resistant to EOs than gram-positive bacteria; as shown by the findings of the present study.

\section{Conclusions}

In this study, $M$. officinalis EO was extracted using Clevenger and hydro distillation technique. A GC-MS analysis of M. officinalis EO detected 22 compounds, representing $96.7 \%$ of the total oil composition. Major composition of the M. officinalis EO included geranyl acetate (27.9\%), citral (14.2\%), Z-citral (9.8\%) citronellal (8.4\%) and citronellol (7.6\%). Results showed that the smallest IZD on different $M$. officinalis EO concentrations on $P$. aeruginosa. Moreover, results demonstrated that the M. officinalis EO included greater inhibitory effects on commercial strains causing infections, compared to clinical strains. The M. officinalis EO included the greatest effects on gram-positive bacteria. Normally, M. officinalis EO is rich in phenolic compounds and hence an impressive free radical scavenger. Further studies are necessary to investigate potential toxicities of the extracts from $M$. officinalis EO due to the human safety.

\section{Acknowledgement}

The authors wish to express their gratitude to National Elites Foundation for funding this study.

\section{Financial disclosure}

The authors declared no financial interest.

\section{Funding/Support}

This work was financially supported by the National Elites Foundation

\section{References}

1. Ahmad I, Beg AZ. Antimicrobial and phytochemical studies on 45 Indian medicinal plants against multidrug resistant human pathogens. Journal of Ethnopharmacology. 2001; 74:113-123.

2. Babayi H, Kolo I, Okogun J, Ijah U. The antimicrobial activities of methanolic extracts of Eucalyptus camaldulensis and Terminalia catappa against some pathogenic microorganisms. Biokemistri 2004; 16(2):106-111.

3. Abeysinghe $\mathrm{P}$, Pathirana $\mathrm{R}$, Wanigatunge $\mathrm{R}$. Evaluation of antibacterial activity of different mangrove plant extracts. Ruhuna Journal of Science. 2012;1: 104-111.

4. Sureshjani MH, Yazdi FT, Mortazavi SA, Alizadeh Behbahani B, Shahidi F. Antimicrobial effects of Kelussia odoratissima extracts against food borne and food spoilage bacteria" in vitro". Journal of Paramedical Sciences. 2014;5(2): 115-120.

5. Yazdi FT, Alizadeh Behbahani B. Antimicrobial effect of the aqueous and ethanolic Teucrium polium L. extracts on gram positive and gram-negative bacteria "in vitro". Journal of Paramedical Sciences. 2013;4(4); $55-61$.

6. Alizadeh Behbahani B, Yazdi FT, Mortazavi A, Gholian MM, Zendeboodi F, Vasiee A. Antimicrobial effect of Carboxy Methyl Cellulose (CMC) containing aqueous and ethanolic Eucalyptus camaldulensis L. leaves extract against Streptococcus pyogenes, Pseudomonas aeruginosa and Staphylococcus epidermidis. Journal of Paramedical Sciences. 2014;5(2):59-69.

7. Shakeri A, Khakdan F, Soheili V, Sahebkar A, Shaddel R, Asili J. Volatile composition, antimicrobial, cytotoxic and antioxidant evaluation of the essential oil from Nepeta sintenisii Bornm. Industrial Crops and Products. 2016; 84:224-229.

8. Sun J, Wang X, Wang P, Li L, Qu W, Liang J. Antimicrobial, antioxidant and cytotoxic properties of essential oil from Dictamnus angustifolius. Journal of Ethnopharmacology. 2015; 159:296-300.

9. Yu J, Lei J, Yu H, Cai X, Zou G. Chemical composition and antimicrobial activity of the essential oil of Scutellaria barbata. Phytochemistry. 2004; 65:881-884

10. Yıldırım A, Mavi A, Oktay M, Kara AA, Algur OF, Bilaloglu V. Comparison of antioxidant and antimicrobial activities of Tilia (Tilia argentea Desf ex DC), sage (Salvia triloba L.), and Black tea (Camellia sinensis) extracts. Journal of Agricultural and Food Chemistry. 2000; 48:5030-5034.

11. Uddin N, Islam R, Hasan N, Hossain MS, Roy A, Hossain MM, et al. DPPH scavenging assay of eightyfour Bangladeshi medicinal plants. IOSR-JPBS. 2011; 6:66-73

12. Dra LA, Brahim MAS, Boualy B, Aghraz A, Barakate M, Oubaassine S, et al. Chemical composition, antioxidant and evidence antimicrobial synergistic effects of Periploca laevigata essential oil with conventional antibiotics. Industrial Crops and Products. 2017; 109:746-752.

13. Alizadeh Behbahani B, Yazdi FT, Shahidi F, Noorbakhsh H, Vasiee A, Alghooneh A. Phytochemical analysis and antibacterial activities 
extracts of mangrove leaf against the growth of some pathogenic bacteria. Microbial Pathogenesis. 2018; 114:225-232.

14. Chung MJ, Cho S-Y, Bhuiyan MJH, Kim KH, Lee S-J. Anti-diabetic effects of lemon balm (Melissa officinalis) essential oil on glucose-and lipidregulating enzymes in type 2 diabetic mice. British Journal of Nutrition. 2010; 104:180-188.

15. Sousa AC, Gattass CR, Alviano DS, Alviano CS, Blank AF, Alves PB. Melissa officinalis L. essential oil: antitumoral and antioxidant activities. Journal of Pharmacy and Pharmacology. 2004; 56: 677-681.

16. Sadraei H, Ghannadi A, Malekshahi K. Relaxant effect of essential oil of Melissa officinalis and citral on rat ileum contractions. Fitoterapia. 2003; 74: 445-452.

17. Pouyanfar E, Hadian J, Akbarzade M, Hatami M, Kanani MR, Ghorbanpour M. Analysis of phytochemical and morphological variability in different wild-and agro-ecotypic populations of Melissa officinalis L. growing in northern habitats of Iran. Industrial Crops and Products. 2018; 112:262273.

18. Petretto G, Fancello F, Bakhy K, Faiz CA, Sibawayh $\mathrm{Z}$, Chessa $\mathrm{M}$, et al. Chemical composition and antimicrobial activity of essential oils from Cuminum cyminum L. collected in different areas of Morocco. Food Bioscience. 2018; 22: 50-58.

19. Noshad M, Hojjati M, Behbahani BA. Black Zira essential oil: Chemical compositions and antimicrobial activity against the growth of some pathogenic strain causing infection. Microbial Pathogenesis. 2018; 116:153-157.

20. Alizadeh Behbahani B, Shahidi F, Yazdi FT, Mortazavi SA, Mohebbi M. Antioxidant activity and antimicrobial effect of tarragon (Artemisia dracunculus) extract and chemical composition of its essential oil. Journal of Food Measurement and Characterization. 2017; 11:847-863.

21. Alizadeh Behbahani B, Yazdi FT, Vasiee A, Mortazavi SA. Oliveria decumbens essential oil: Chemical compositions and antimicrobial activity against the growth of some clinical and commercial strains causing infection. Microbial Pathogenesis. 2018; 114:449-452.

22. Chemsa AE, Zellagui A, Ozturk M, Erol E, Ceylan Ozgu, Duru ME, Lahouel M, Chemical composition, antioxidant, anticholinesterase, antimicrobial and antibiofilm activities of essential oil and methanolic extract of Anthemis stiparum subsp. sabulicola (Pomel) Oberpr, Microbial Pathogenesis (2018), doi: 10.1016/j.micpath.2018.04.033

23. Alizadeh Behbahani B, Imani Fooladi AA. Shirazi balangu (Lallemantia royleana) seed mucilage: Chemical composition, molecular weight, biological activity and its evaluation as edible coating on beefs. International Journal of Biological Macromolecules. 2018; 114:882-889.
24. Alizadeh Behbahani B, Yazdi FT, Shahidi F, Hesarinejad MA, Mortazavi SA, Mohebbi M. Plantago major seed mucilage: Optimization of extraction and some physicochemical and rheological aspects. Carbohydrate Polymers. 2017; 155:68-77.

25. Ozturk M, Kolak U, Topcu G, Oksuz S, Choudhary MI. Antioxidant and anticholinesterase active constituents from Micromeria cilicica by radicalscavenging activity-guided fractionation. Food Chemistry. 2011; 126:31-38.

26. Vasiee A, Alizadeh Behbahani B, Yazdi FT, Moradi S. Optimization of the production conditions of the lipase produced by Bacillus cereus from rice flour through Plackett-Burman Design (PBD) and response surface methodology (RSM). Microbial Pathogenesis. 2016; 101:36-43.

27. Alizadeh Behbahani B, Imani Fooladi AA. Development of a novel edible coating made by Balangu seed mucilage and Feverfew essential oil and investigation of its effect on the shelf life of beef slices during refrigerated storage through intelligent modeling. Journal of Food Safety. 2018; e12443. https:// doi.org/10.1111/jfs.12443.

28. Alizadeh Behbahani B, Tabatabaee Yazdi F, Shahidi F, Mortazavi SA, Mohebbi M. Principle component analysis (PCA) for investigation of relationship between population dynamics of microbial pathogenesis, chemical and sensory characteristics in beef slices containing Tarragon essential oil. Microbial Pathogenesis. 2017; 105:37-50.

29. Alizadeh Behbahani B, Shahidi F, Yazdi FT, Mortazavi SA, Mohebbi M. Use of Plantago major seed mucilage as a novel edible coating incorporated with Anethum graveolens essential oil on shelf life extension of beef in refrigerated storage. International Journal of Biological Macromolecules. 2017; 94:515526.

30. Alizadeh Behbahani B, Yazdi FT, Noorbakhsh H, Riazi F, Jajarmi A, Yazdi FT. Study of the antibacterial activity of methanolic and aqueous extracts of Myrtus communis on pathogenic strains causing infection. Zahedan Journal of Research in Medical Sciences. 2016;18 (2):1-7.

31. Clinical and Laboratory Commercials Institute (CLSI), 2006a. (CLSI Document M7-A7). Methods for Dilution Antimicrobial Susceptibility Tests for Bacteria That Grow Aerobically; Approved Commercial, seventh ed. Clinical and Laboratory Commercials Institute, Wayne, PA.

32. Clinical and Laboratory Commercials Institute (CLSI), 2006b. (CLSI Document M27-A3). Reference Method for Broth Dilution Antifungal Susceptibility Testing of Yeasts; Approved Commercial, second ed. Clinical and Laboratory Commercials Institute, Wayne, PA.

33. Clinical and Laboratory Commercials Institute (CLSI), 2006c. (CLSI Document M38-A). Reference Method for Broth Dilution Antifungal Susceptibility Testing of 
Filamentous Fungi; Approved Commercial, second ed. Clinical and Laboratory Commercials Institute, Wayne, PA.

34. Zomorodian K, Saharkhiz J, Pakshir K, Immeripour Z, Sadatsharifi A. The composition, antibiofilm and antimicrobial activities of essential oil of Ferula assafoetida oleo-gum-resin. Biocatalysis and Agricultural Biotechnology. 2018; 14: 300-304.

35. Alizadeh Behbahani B, Imani Fooladi AA. Evaluation of phytochemical analysis and antimicrobial activities Allium essential oil against the growth of some microbial pathogens. Microbial Pathogenesis. 2018; 114: 299-303.

36. Alizadeh Behbahani B, Imani Fooladi AA. Antibacterial activities, phytochemical analysis and chemical composition Makhlaseh extracts against the growth of some pathogenic strain causing poisoning and infection. Microbial Pathogenesis. 2018; 114:204208.

37. Wiegand I, Hilpert K, Hancock RE. Agar and broth dilution methods to determine the minimal inhibitory concentration (MIC) of antimicrobial substances. Nature Protocols. 2008; 3:163.

38. Alghooneh A, Alizadeh Behbahani B, Noorbakhsh H, Yazdi FT. Application of intelligent modeling to predict the population dynamics of Pseudomonas aeruginosa in Frankfurter sausage containing Satureja bachtiarica extracts. Microbial Pathogenesis. 2015; 85:58-65.

39. Farahani HA, Valadabadi SA, Daneshian J, Khalvati MA. Evaluation changing of essential oil of balm (Melissa officinalis L.) under water deficit stress conditions. Journal of Medicinal Plants Research. 2009; 3:329-333.

40. Mimica-Dukic N, Bozin B, Sokovic M, Simin N. Antimicrobial and antioxidant activities of Melissa officinalis L. (Lamiaceae) essential oil. Journal of Agricultural and Food Chemistry. 2004; 52:24852489.
41. Adinee J, Piri K, Karami O. Essential oil component in flower of lemon balm (Melissa officinalis L.). American Journal of Biochemistry and Biotechnology. 2008; 4:277-278.

42. Uyanik M, Gurbuz B. Chemical diversity in essential oil Compositions of Leaf, Herb and Flower in Lemon Balm (Melissa officinalis L.). Turkish Journal of Agricultural and Natural Sciences. 2014; 1:210-214.

43. BoZoviC M, Garzoli S, Baldisserotto A, Romagnoli C, Pepi F, Cesa S, et al. Melissa officinalis L. subsp. altissima (Sibth. \& Sm.) Arcang. essential oil: Chemical composition and preliminary antimicrobial investigation of samples obtained at different harvesting periods and by fractionated extractions. Industrial Crops and Products. 2018; 117:317-321.

44. Subashini R, Mahesh V, Kavitha A, Geethanjali B, Umamaheshwari S. Comparative evaluation of antimicrobial activity of selected three herbal plants extract with digital Image Processing. EJB I9. 2013; 2:14-26.

45. Rukayadi Y, Lau K, Zainin N, Zakaria M, Abas F. Screening antimicrobial activity of tropical edible medicinal plant extracts against five commercial microorganisms for natural food preservative. International Food Research Journal. 2013; 20:2905.

46. Tabatabaei-Yazdi F, Alizadeh-Behbahani B, Zanganeh H. The Comparison Among Antibacterial Activity of Mespilus germanica Extracts and Number of Common Therapeutic Antibiotics “In Vitro". Zahedan Journal of Research in Medical Sciences. 2015;17(12):1-6.

47. Yeganegi M, Yazdi FT, Mortazavi SA, Asili J, Behbahani BA, Babaei AB. Equisetum telmateia extracts: Chemical compositions, antioxidant activity and antimicrobial effect on the growth of some pathogenic strain causing poisoning and infection. Microbial Pathogenesis. 2018; 116:62-67. 